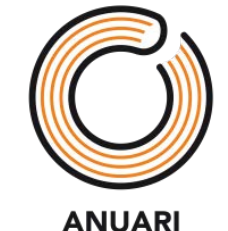

DE BIBLIOTEQUES,

LLIBRES I LECTURA

Marga Losantos

mlosantos@bnc.cat

Biblioteca de Catalunya

\title{
HISTÒRIA DE LES BIBLIOTEQUES I ARXIUS A CATALUNYA (2018-2019)
}

\author{
HISTORIA DE LAS BIBLIOTECAS Y ARCHIVOS \\ EN CATALUÑA (2018-2019)
}

HISTORY OF LIBRARIES AND ARCHIVES

IN CATALONIA (2018-2019) 


\section{RESUM | RESUMEN | ABSTRACT}

En aquest article es presenten les principals publicacions, estudis i activitats al voltant de la història de les biblioteques i dels arxius, així com les que parlen de les seves col-leccions i fons, editades a Catalunya el 2018 i 2019 o que tracten sobre Catalunya. S'hi inclouen tant les monografies com els articles, tesis i treballs de recerca que s'han publicat; també es recullen les conferències i els congressos duts a terme i la docència relacionada.

En este artículo se presentan las principales publicaciones, estudios y actividades en relación con la historia de las bibliotecas y los archivos, así como las que hablan de sus colecciones y sus fondos, editadas en Cataluña el 2018 y 2019, o que tratan sobre Cataluña. Se incluyen tanto las monografías como los artículos, tesis y trabajos de investigación que se han publicado; también se recogen las principales exposiciones realizadas con fondo de las bibliotecas y archivos, las conferencias y los congresos que se han realizado y la docencia relacionada.

This article reviews the literature on the history of libraries, archives and collections published in Catalonia in 2018 and 2019 or referring to the Catalan sector in that period. This literature includes a variety of monographs, articles, theses and research projects, as well as exhibitions and reports on conferences and teaching activities.

PARAULES CLAU:

Història de les biblioteques, Història dels arxius, Biblioteques catalanes, Arxius catalans

PALABRAS CLAVE:

Historia de las bibliotecas, Historia de los archivos, Bibliotecas catalanas, Archivos catalanes

KEYWORDS:

History of libraries, History of archives, Catalan libraries, Catalan archives 


\section{PRESENTACIÓ}

Aquest bienni conclou la celebració del centenari dels esdeveniments que van posar el fonament al sistema bibliotecari català. Es va iniciar el 2014 amb la commemoració de la inauguració de la Biblioteca de Catalunya, i va continuar el 2015 recordant l'aprovació del projecte de la Mancomunitat per desplegar la xarxa de biblioteques públiques i la creació de l'Escola de Bibliotecàries. Ara celebrem que el 1918 s'inauguraven les primeres biblioteques, distribuïdes pel territori: Olot, les Borges Blanques, Sallent i Valls, i el 1919 la biblioteca de Canet.

Més enllà de les publicacions i actes fruit d'aquestes commemoracions, en termes generals, ha continuat la tònica de parlar més dels fons de les biblioteques i arxius que de la seva història.
La Generalitat de

Catalunya ha

elaborat la pàgina

web 100 anys de

biblioteques

populars

\section{PUBLICACIONS}

\subsection{Biblioteques}

La Generalitat de Catalunya ha elaborat la pàgina web 100 anys de biblioteques populars, que presenta la història de la creació de les cinc primeres biblioteques públiques, el recull dels actes que cada municipi ha dut a terme per celebrar-ho $i$ algunes de les publicacions que se n'han editat, com el llibret sobre la biblioteca d'Olot, de Carme Simon i Antoni Mayans, o la recopilació de textos sobre la biblioteca de Valls, elaborada per Laura Canalias, Lluís Cuspinera, Jep Martí, Jordi París i Núria Ventura. La majoria dels textos fan menció als dietaris de les bibliotecàries, que ens han deixat la història petita de les biblioteques i que en molts casos es poden consultar digitalitzats.

L'Ajuntament de les Borges Blanques ha editat un opuscle sobre la biblioteca, escrit per Montse Esteller, Marc Macià i Josep Varela; també ho ha fet el de Sallent, que dedica un número monogràfic de la col-lecció Patrimoni Sallentí a la història de la seva biblioteca. Pep Martí Baiget, a Cultura i paisatge a la ruta del Cister, escriu un breu article sobre la biblioteca de Valls, i Ramon Erra ha fet el text d'una de les petites històries de l'editorial Mediterrània sobre la biblioteca de Canet de Mar, il.lustrada, com totes elles, per Pilarín Bayés.

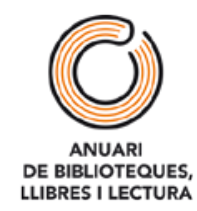


A banda dels estudis sobre les cinc biblioteques públiques, trobem algun treball més sobre les biblioteques catalanes. En l'àmbit universitari, podem destacar la monografia publicada per la Universitat de Barcelona sobre la història de la informatització dels fons documentals de la biblioteca de la Universitat de Barcelona, Petita història de Procés Tècnic: una visió de la informatització dels fons documentals a la Universitat de Barcelona. Es tracta d'un projecte que s'inicia el 1979 i que va ser pioner a Espanya. La seva autora, Enriqueta Jansà, ha estat una de les responsables de tirar-ho endavant, i hi va treballar des dels inicis del projecte fins al 2009.

Tot i que no forma part de les biblioteques públiques centenàries, és interessant recollir l'article que Sònia Fernández Dobón publica a Guix, sobre la biblioteca Can Butjosa de Parets del Vallès i el seu Pla de foment de la lectura. La biblioteca, que el 2018 va fer trenta-cinc anys, en fa vint-i-cinc que té un pla de foment de la lectura que continua sent una experiència innovadora, tant per la metodologia que utilitza com pel punt d'inflexió que representa.

Les biblioteques no sempre han d'estar dins un local tancat; també les podem trobar a l'aire lliure, com un servei d'extensió bibliotecària. Aquest és el cas dels bancs biblioteca del passeig de Sant Joan de Barcelona, els anys 1930, que Teresa Mañà descriu a la revista BiD, a més de presentar altres iniciatives similars, a Espanya i als Estats Units.

Com ja és habitual, les publicacions sobre la història de les biblioteques han donat pas als estudis sobre els seus fons, molt més abundants.

L'important fons de fullets de tema sanitari de la biblioteca de la Facultat de Medicina de la Universitat de Barcelona (UB) ha estat objecte d'un extens estudi de Jacint Corbella i quatre investigadors més a la revista Gimbernat, on presenten alguns autors i les temàtiques.

Javier Antón estudia a la revista Memoria y Civilización la repercussió que va tenir en el patrimoni bibliogràfic de Catalunya la desamortització de finals del segle XVIII i la primera meitat del XIX. Moltes de les biblioteques conventuals van ser destruïdes $i$ espoliades, $i$ els fons que van quedar van anar a parar a les biblioteques episcopals o públiques o, com en el cas de Barcelona, a la biblioteca universitària, que era al mateix temps provincial.

Yolanda Ruiz ha estudiat l'origen de la biblioteca Joaquim Folch i Torres del MNAC, inaugurat el $1891 \mathrm{com}$ a museu de reproduccions artístiques. A la revista Matèria, del Departament d'Història de l'Art de la Universitat de Barcelona, descriu les importants compres que Salvador Sanpere i Miquel va fer el 1890, que fan palesa la voluntat de crear una biblioteca auxiliar al Museu.

Àngels Rius presenta una relació dels llibres procedents de la biblioteca per als soldats durant la Guerra Civil que es conserven a la biblioteca de Montserrat, amb una breu descripció de la seva procedència i, en el cas
Com ja és habitual, les publicacions sobre la història de les biblioteques han donat pas als estudis sobre els seus fons, molt més abundants

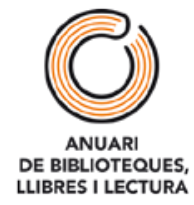


d'alguns d'ells, la indicació de la nota «prohibit», ja fos el llibre en concret o l'autor.

Irene Capdevila, a la revista Mot so Razo, ofereix la transcripció paleogràfica i l'edició de la traducció catalana del Breviari d'amor d'Ermengaud, a partir de la reproducció del manuscrit perdut de la biblioteca del Palau Reial de Barcelona, que es troba al fons Miquel i Planas de reproduccions fotogràfiques de la Biblioteca de Catalunya.

Com en anys anteriors, la Miscel/lània Litúrgica Catalana recull estudis sobre els fons de les biblioteques i arxius catalans. Miquel Torras parla sobre el catàleg de manuscrits del segle XVIII de la biblioteca de l'Arxiu Capitular de Vic, recollits per Jaume Pasqual al Sacrae Antiquitatis Cataloniae Monumenta (Biblioteca de Catalunya. Ms. 729).

Trobem també un extens treball sobre l'anamnesi de l'anomenada Anàfora de Barcelona (P.Monts.Roca. 128-178), de la biblioteca del Monestir de Montserrat, per Sebastià Janeras.

Per la seva banda, Miquel dels Sants Gros descriu els quaranta fragments manuscrits de passioners i leccionaris del santoral, dels segles IX-XIII, que es conserven a la Biblioteca Episcopal de Vic. Són peces valuoses, perquè no se n'ha conservat cap d'íntegre. Justament, en un d'aquests fragments Jesús Alturo i Tània Alaix han identificat i descrit el manuscrit més antic fins ara conegut de la Vita et passio sancti Desiderii de Sisebut, conservada en un passioner copiat a final del segle $x$ pel sacerdot Isarn per a ús de la catedral de Vic.

Els mateixos Alturo i Alaix, a la revista Ausa, també estudien el manuscrit 197 de la Biblioteca Episcopal de Vic, que transmet les obres de Virgili. Els autors plantegen la idea, que els estudiosos anteriors no havien tingut en compte, que el text fos autòcton de Vic, copiat a mitjans del segle XI pel gramàtic Borrell Guibert.

Els fons de la Biblioteca de Catalunya (BC) han estat objecte de diversos estudis, com el de Josep Maria Salisi a la Revista de Musicologia de Catalunya, sobre l'obra de Joan Cererols al fons Verdú de la Biblioteca de Catalunya (M 1168 i M 163) o el d'Anna Maria Anglada, a la mateixa revista, que estudia l'obra del compositor Miguel Casals Aragonés, a partir de la descripció del seu fons.

A banda dels manuscrits musicals, també trobem estudis sobre altres textos, com el que fa Patricia Cañizares a la Revista de Estudios Latinos. Cañizares treballa a fons el manuscrit 3171 de la BC, que conté una col-lecció de narracions breus de caràcter miraculós i exemplar, algunes d'elles inèdites. El personal de la Biblioteca també ha treballat els seus fons. Anna Gudayol, cap de la Secció de Manuscrits, explica breument a Plecs d'Història Local la història de l'arribada dels cançoners Vega a la Biblioteca, i la seva importància.

\section{Com en anys \\ anteriors, la \\ Miscel·lània \\ Litúrgica Catalana \\ recull estudis sobre \\ els fons de les \\ biblioteques i arxius \\ catalans}


Els blogs de les diferents biblioteques sovint descriuen els seus fons, bé sigui perquè acaben d'arribar o perquè se'n vol fer una difusió especial. Solen ser ressenyes breus, però es tracta d'una informació que difícilment trobarem a altres llocs. Per exemple, els blogs dels CRAI de Lletres (Bloc de Lletres), del Pavelló de la República i de la Biblioteca de Reserva de la Universitat de Barcelona.

En relació amb el personal, Josep Dolcet fa l'obituari de Josep Maria Llorens, musicòleg i sacerdot. Llorens va ser un dels últims representants de la musicologia clàssica, i la majoria de musicòlegs catalans actuals s'han format amb ell. Va dirigir l'Instituto Español de Musicologia del CSIC, i el Departament de Música de la Biblioteca de Catalunya, després de Felip Pedrell i Higini Anglès, i va continuar la seva obra. Va donar classes al Conservatori del Liceu, i va impartir multitud de conferències i cursos; ens ha deixat tot un seguit de publicacions, tant al CSIC com a la Biblioteca de Catalunya, entre elles les obres completes dels polifonistes espanyols del Segle d'Or.

Per altra banda, com en biennis anteriors, s'han incorporat biografies de bibliotecaris i bibliotecàries a la Viquipèdia, alhora que s'han actualitzat les que ja hi havia. Algunes de les noves incorporacions són les de Ferran Burguillos, actualment gerent del Consorci de Biblioteques de Barcelona; Pilar Bertran Vallès, primera directora de la biblioteca popular de Manresa; Rosa Granès, que va treballar al Servei de Biblioteques del Front; Carme Illa i Munné, professora de l'Escola de Bibliotecàries i bibliotecària de la biblioteca pública Arús; Montserrat Soler, professora de l'Escola i bibliotecària a la Biblioteca de Catalunya, o Lolita Mirabent, directora de la biblioteca Santiago Rusiñol des de 1951 i d’altres.

\subsection{Arxius}

$\mathrm{Hi}$ ha tres arxius que han celebrat aniversaris aquests dos anys: l'Arxiu Històric de Tarragona, creat el 1944, que commemora els setanta-cinc anys; el del Col-legi d'Arquitectes de Catalunya, que el 2019 ha celebrat els cinquanta anys, i l'Arxiu General de la Corona d'Aragó, que es va crear fa set-cents anys. En el cas de Tarragona, l'aniversari s'ha celebrat amb un seguit d'actes i esdeveniments: exposicions, xerrades i jornades, i s'ha publicat un llibret que ho recull tot (75 anys de l'Arxiu Històric de Tarragona). L'Arxiu Històric del Col-legi d'Arquitectes de Catalunya ha fet una gran festa. I, per la seva banda, el Departament de Cultura de la Generalitat ha declarat commemoració oficial la celebració dels set-cents anys de la creació de l'Arxiu General de la Corona d'Aragó.

Alguna de les commemoracions del bienni anterior ha tingut continuïtat en aquest, com és el cas del centenari de l'Arxiu Històric de la ciutat, sobre el qual s'ha publicat un volum amb la història de la Casa de l'Ardiaca, i un capítol dedicat a l'arxiu, per Sebastià Riera. També l'Any Puig i Cadafalch ha tingut una darrera publicació. L'arxiver Ramon Planes ha recollit, publicats
Com en biennis

anteriors, s'ha

seguit treballant

amb continguts a la

Viquipèdia i, per

exemple, s'han

seguit incorporant

biografies de

bibliotecaris i

bibliotecàries 
per l'Arxiu Comarcal del Solsonès, uns articles sobre la història de la col-lecció de l'arquitecte i el seu contingut.

El 2018 s'ha publicat un volum sobre l'Arxiu dels Marquesos de Santa Maria de Barberà, que es conserva al castell de Vilassar de Dalt. Entre altres col·laboracions presenta la història de l'arxiu, per Coral Cuadrada. A més, la mateixa Cuadrada, juntament amb Daniel Duran i Alejandro MartínezGiralt, han publicat el catàleg del fons Llull de l'arxiu. El fons conté la documentació de la nissaga Llull de Barcelona, des del segle xiii al xvii, amb pergamins i fulls en paper d'importància singular: I'única còpia coneguda del testament del beat Ramon Llull i referències rellevants a l'Escola Lul.liana barcelonina.

Igual que en els biennis anteriors, els treballs sobre la història dels arxius, escadussers, deixen lloc als estudis sobre els fons dels arxius, més abundants.

L'Arxiu Municipal de Castelldefels ha presentat un treball coordinat per Juanjo Vas, amb diferents estudis, que transcriu i estudia el document més antic que conserva, un pergamí de 1588, el capbreu de Pere Térmens del fons Salvador Savall, que recull escriptures públiques on es reconeixen els drets que tenien els senyors feudals sobre les seves terres, en aquest cas el baró de l'Eramprunyà.

Els arxius tenen tipologies de documents molt diverses, $\mathrm{i}$ a vegades poc conegudes, com la col-lecció de baralles i naips que ha aplegat l'Arxiu Històric de la Ciutat de Barcelona al llarg dels anys. Esther Sarrà i Paloma Sánchez en publiquen el catàleg, on es descriu i estudia la col-lecció, que conté alguns documents que destaquen per la seva riquesa i originalitat.

El Departament d'Art i Musicologia de la Universitat Autònoma de Barcelona (UAB) ha continuat la publicació dels Inventaris de Fons Musicals de Catalunya, que va començar el 2007 sota el patrocini de la Subdirecció General de Patrimoni de la Generalitat de Catalunya, i es va publicar en règim de coedició entre 2010 i 2011, i com a col-lecció pròpia de la UAB a partir de 2012. El darrer volum, el desè de la col-lecció, ha estat dirigit per Josep Maria Gregori. Després d'anys de treballar-hi, amb l'ajut dels estudiants de Musicologia de la UAB, Josep M. Gregori presenta el catàleg de les col-leccions de manuscrits i impresos que configuren el fons musical de l'Arxiu de la Catedral de Girona; així mateix, presenta un estat de la qüestió sobre la historiografia musical relacionada amb la catedral.

A banda de la publicació dels IFMuC, diversos investigadors han treballat altres fons musicals, com Jaume Pinyol, que fa una aproximació a les biografies dels intèrprets de la capella de música de la catedral de Girona entre els segles XVII i XIX, a partir de les partitures de l'arxiu musical de la capella.

Els fons de l'Arxiu Comarcal de la Garrotxa també han rebut l'atenció dels investigadors. En aquest cas, d'Aurèlia Pessarrodona, que estudia la

\section{Els treballs sobre la història dels arxius, escadussers, deixen Iloc als estudis sobre els fons dels arxius, més abundants}


presència d'una trentena de manuscrits amb números d'òpera italiana del segle XVIII $\mathrm{i}$ inicis del segle XIX al fons musical de Sant Esteve d'Olot (Arxiu Comarcal de la Garrotxa). Atesa la mancança de fonts musicals operístiques d'aquest període al Principat, aquesta troballa resulta especialment rellevant.

La Fundació Noguera ha continuat la publicació de la documentació dels arxius catalans, en aquest cas amb el diplomatari de la catedral de Tortosa durant els episcopats de Ponç de Torrella (1212-1254) i Bernat d'Olivella (1254-1272).

Jaume de Puig reedita als Annals de I'Institut d'Estudis Gironins cinc documents del segle $X$, salvats de l'arxiu de Ripoll gràcies a una transcripció anònima del segle XVIII, el manuscrit 161 de l'Arxiu de la Catedral de Girona.

Jordi Enfedaque, a la revista Beceroles: Lletres de Llengua i Literatura, descriu la història i tractament del fons documental de l'escriptor Sebastià Juan Arbó, al Servei d'Arxiu Municipal de Sant Carles de la Ràpita.

L'Arxiu Municipal de Granollers conserva diversos fons d'empreses que permeten conèixer una part significativa del passat industrial de la ciutat. En aquest cas, Anna Maimir presenta el fons documental de l'empresa Unitesa (1958-1967), que correspon a l'última etapa de la fàbrica Can Comas, i fa una breu explicació de l'evolució de la fàbrica en el context del desenvolupament de la indústria tèxtil a Granollers.

La Revista de Treball Social publica l'article de J. A. López Rodríguez sobre la recuperació de I'Arxiu de I'Escola de Treball Social de la Universitat de Barcelona, que conserva documentació prèvia a l'any de la constitució oficial de l'Escola (1953). L'article ressegueix el recorregut històric de I'Escola de Treball Social de Barcelona per contribuir a la contextualització en la qual sorgeix i les influències posteriors.

El Centre d'Estudis Comarcals del Segrià organitza cada any unes jornades sobre la comarca, i per recollir els treballs que s'hi presenten publica la revista Shikar. Els investigadors són uns grans usuaris dels fons arxivístics, tant els de la comarca com d'altres, i en alguns casos els estudien, com ara l'article de Josep M. Salisi, sobre un conjunt de composicions de músics i mestres de capella que havien exercit a la catedral de Lleida i que es conserven a l'Arxiu Capitular de la Catedral d'Albarrasí. També Mònica Sesma hi publica un breu article on descriu els diferents fons documentals que han ingressat a l'Arxiu Municipal de Lleida provinents de famílies, entitats, associacions i empreses lleidatanes.

És interessant tenir en compte l'ANC: Butlletí de l'Arxiu Nacional de Catalunya, que a cada número fa una presentació d'algun fons, com el de Víctor Castells, imprescindible per al coneixement de la història de l'exili català; el de les fitxes de salvament de patrimoni artístic durant la Guerra Civil, que han permès seguir la pista a dues peces relacionades amb el tràfic il-lícit d'obres d'art, o el dels arxius dels fotògrafs Pere Català Pic i Pere

Cada vegada més cal tenir en compte la informació sobre els fons que proporcionen els blogs dels arxius, encara que siguin ressenyes breus 
Català Roca. Cal destacar també la relació exhaustiva dels fons ingressats, amb una descripció molt completa de cadascun.

També s'ha de tenir en compte la informació sobre els fons que proporcionen els blogs dels arxius, encara que siguin ressenyes breus. El blog Arxivae, dels Arxius de la comarca de l'Alt Empordà, continua difonent els fons dels seus arxius, i gairebé cada mes presenten un document, on es descriuen les dades arxivístiques, la història arxivística i el contingut.

\section{ESTUDIS I DOCÈNCIA}

\subsection{Docència}

Els estudis de biblioteconomia i documentació de les universitats catalanes continuen posant poca atenció a la història de les biblioteques i dels arxius en els plans d'estudis; en el cas de la UB, però, s'ofereix una assignatura optativa, Patrimoni Documental: Institucions de la Memòria, Serveis i Usuaris.

En el cas dels màsters universitaris, tant als de la Facultat d'Informació i Mitjans Audiovisuals de la UB com al d'Arxivística de la UAB, podem trobar estudis que si bé no tracten estrictament el tema que ens pertoca, s'hi apropen.

Així, la Facultat d'Informació i Mitjans Audiovisuals de la UB ha continuat impartint el bienni 2018-2019 el màster universitari de Biblioteques i Col-leccions Patrimonials, adreçat a graduats de diferents titulacions i basat en la interdisciplinarietat. S'orienta a la gestió, el tractament, la difusió i la promoció del patrimoni, amb la finalitat de formar professionals que dominin els processos i les tècniques de creació, anàlisi, gestió i avaluació d'informació. S'imparteixen assignatures com El Patrimoni Bibliogràfic i Documental Europeu; Fons Personals Patrimonials; Fons i Col-leccions Fotogràfics, Sonors i de Cinema, i Centres Patrimonials.

També l'Escola Superior d'Arxivística i Gestió de Documents de la UAB ha impartit el curs 2018-2019 el màster universitari d'Arxivística i Gestió de Documents, que proporciona una formació integrada en el camp de l'arxivística i la gestió de documents que capacita els alumnes per al desenvolupament del seu treball en organitzacions públiques i privades, tant amb documents de caràcter històric com administratius i en qualsevol tipus de suport.

La Facultat Antoni Gaudí d'Història, Arqueologia i Arts Cristianes ha començat a impartir el 2019 el màster de Patrimoni Musical Litúrgic, amb assignatures com Fons Musicals Eclesiàstics.

\section{Els màsters}

universitaris, tant

els de la Facultat

d'Informació i

Mitjans Audiovisuals

de la UB com el

d'Arxivística de la

UAB, tenen alguna

assignatura que

posa l'atenció a la

historia de les

biblioteques si els

arxius 


\subsection{Treballs i tesis}

Aquest bienni els treballs i tesis relacionats amb la història de les biblioteques i els arxius han estat escassos. En canvi, en trobem sobre els fons de biblioteques i arxius, ja siguin tesis doctorals o treballs de final de grau o màster. En aquest sentit, cal destacar l'augment de treballs de final de grau o màster sobre els fons de les biblioteques $\mathrm{i}$ arxius del màster d’Arxivística de l'Escola Superior d'Arxivística i Gestió de Documents de la UAB i de l'Escola Superior de Música de Catalunya.

Entre els treballs sobre les biblioteques trobem la tesi de Maite Comalat, sobre el servei de bibliobusos a Espanya, dirigida per Teresa Mañà. Tot i que l'objectiu de Comalat és analitzar l'evolució dels bibliobusos a Espanya, presentant la situació actual, i elaborar unes recomanacions d'actuacions futures, és interessant ressenyar el capítol dedicat als antecedents i la història d'aquest servei a Espanya i sobretot a Catalunya.

Així mateix és interessant el treball final del grau d'Informació i Documentació de Neus Castellano, dirigit també per Teresa Mañà. Castellano estudia el Servei de Documentació de Literatura Infantil i Juvenil (SDLIJ) de la biblioteca Xavier Benguerel de Barcelona. Igual que en el cas anterior, l'objectiu del treball no és fer la història del servei, però el capítol que se li dedica és prou important com perquè valgui la pena ressenyar-lo aquí. El SDLIJ té els seus orígens el 1940, a la biblioteca infantil de la Santa Creu, i des del 2004 és un servei de Biblioteques de Barcelona adscrit a la biblioteca Xavier Benguerel.

Andrea Puentes Blanco, en la tesi doctoral dirigida per Emilio Ros-Fábregas, estudia vint llibres manuscrits de polifonia sacra renaixentista que es conserven a la Biblioteca de Catalunya i al Centre de Documentació de I'Orfeó Català, i n'explora la relació amb la vida musical a Barcelona durant aquell període. La música també és la protagonista del treball de final de grau a l'Escola Superior de Música de Catalunya (ESMUC) de Francesc Xavier Ventosa Molner, que analitza els usos musicals a la Cardona del 1700, a partir dels registres de comptabilitat de l'església de Sant Miquel. Un altre treball de I'ESMUC és el treball de final de màster de Laura Planagumà, dedicat a l'estudi d'un cançoner manuscrit (FBB.Manuscrit.12) localitzat a l'Arxiu Parroquial d'Olesa de Montserrat, per contextualitzar-lo històricament, així com per localitzar melodies dels tons indicats en alguns títols («al to de») amb la intenció d’unir-les amb les lletres.

La tesi de Carmen Perrotta reconstrueix la biografia del fotògraf Adolf Mas i del seu arxiu. És interessant, en aquest context, per l'estudi de l'extens arxiu fotogràfic, la seva biblioteca i el fons documental, i per la seva tècnica arxivística, innovadora a l'època.

Els alumnes de l'Escola Superior d'Arxivística i Gestió de Documents han deixat un seguit de treballs de final de màster, en què investiguen els fons de diferents arxius. Jordi Algué (el presenta el 2017 però es publica el 2018) fa una tasca d'anàlisi, descripció i posterior difusió mitjançant una exposició

\section{Aquest bienni \\ trobem diverses tesis doctorals i treballs de final de grau relacionats amb els fons de biblioteques $i$ arxius}

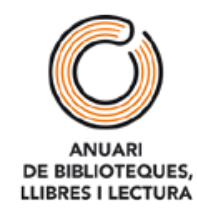


d'un fons de 974 negatius amb retrats de persones que van viure a Cardona durant la Guerra Civil, que es conserven a l'Arxiu Històric de la ciutat. J. Ortiz Ezquerra analitza la donació i el tractament arxivístic de la col-lecció Jubilats de MACOSA-Alstom, formada pels documents ingressats pels antics treballadors de la fàbrica MACOSA del Poblenou a l'Arxiu Municipal del Districte de Sant Martí, fet que contribueix a recuperar una part de la memòria obrera de Barcelona. Sara Martí Pou analitza l'adquisició de béns documentals per part dels centres públics d'arxiu de Catalunya entre 1996 i 2015, a partir del buidat dels expedients de la Junta de Qualificació, Valoració i Exportació de Béns del Patrimoni Cultural de Catalunya i l'anàlisi de les compres. Es tracta d'un treball del 2015, però no s'ha publicat fins al 2019.

Gal·la Pérez López, del màster de Biblioteques i Col·leccions Patrimonials de la Facultat de Biblioteconomia i Documentació, en la memòria final del màster, fa una primera aproximació a l'estudi del circuit de compravenda del llibre d'antiquària a Barcelona, a partir de la correspondència comercial del Ilibreter Josep Porter que es conserva a la Biblioteca de Catalunya.

\subsection{Grups de recerca}

Els grups de recerca de les diferents universitats catalanes no han tractat la història de les biblioteques i els arxius; tanmateix, de la seva recerca en algun cas n'ha sortit una publicació sobre els seus fons, com és el cas de la Càtedra de Patrimoni Musical del Departament d'Art i Musicologia de la UAB i el seu projecte IFMuC, que han tornat a obtenir un ajut de recerca Micinn/Mineco per 2016-2018 per sufragar les despeses d'infraestructura, equipament, dietes i viatges per dur a terme el projecte Patrimonio musical en Gerona: catalogación y estudio de las fuentes musicales conservadas en la catedral, el Archivo Diocesano y el Museo de Arte de Gerona.

En el marc del Grup de Recerca de Patrimoni Cultural trobem un treball, que, tot i ser publicat el 2017, és interessant ressenyar, ja que no es va fer en el seu moment. Es tracta d'un Ilarg text de Joaquim Nadal, publicat inicialment al Butlletí de la Societat Catalana d'Estudis Històrics, i recollit el 2018 a República i Guerra Civil a Girona: estudis i documents, amb textos del mateix autor. El treball estudia la correspondència que van intercanviar Jordi Rubió i Balaguer i Joan Subias i Galter fins a finals de la Guerra Civil, que mostra les seves idees en el camp de les biblioteques públiques i la política bibliotecària de la Mancomunitat i Generalitat. Es tracta de seixanta-tres cartes trobades a l'Arxiu Ramon Muntaner de Figueres, a l'Arxiu Diocesà de Girona i a l'Arxiu de la Diputació de Barcelona.

La Generalitat també ha reconegut, pel període 2017-2020, altres grups de recerca de l'àmbit de la biblioteconomia i la documentació, com són el de Cultura i Continguts Digitals (UB), el de Biblioteques, Educació i Societat (UB) o el de Gestió de la Informació i el Coneixement en les Organitzacions (Universitat Oberta de Catalunya), però cap d'ells ha publicat treballs sobre el tema que ens ocupa.

\author{
Els grups de recerca \\ de les diferents \\ universitats \\ catalanes no han \\ tractat la història de \\ les biblioteques i els \\ arxius; tanmateix, \\ de la seva recerca en \\ algun cas n'ha sortit \\ una publicació sobre \\ els seus fons
}




\section{DIFUSIÓ | DIVULGACIÓ}

\subsection{Congressos}

Un cop més, els congressos que tenen lloc periòdicament a Espanya sobre biblioteques i arxius -IX Congreso Nacional de Bibliotecas Públicas (2018), a Logronyo; les XVI Jornadas Españolas de Información y Documentación de FESABID (2019), a Barcelona; les Jornades Catalanes d'Informació i Documentació (2018), també a Barcelona, o el XVII Congrés d'Arxivística i Gestió de Documents de Catalunya (2019) a Sant Feliu de Guíxols- no han tractat la història de les biblioteques $o$ arxius ni dels seus fons. Tampoc els congressos més sectorials, com pot ser el IX Congreso Nacional de Bibliotecas Móviles (2019), a Segovia.

Hem de fixar-nos en congressos d'altres àmbits per trobar algun treball sobre biblioteques, com les jornades Elias Rogent i Barcelona: Arquitectura, Patrimoni i Restauració, que van tenir lloc el 2017, tot i que el llibre que les recull es publica el 2019. S'hi presenta la comunicació de Marina Ruiz i Neus Verger sobre la biblioteca de la Universitat de Barcelona, que n'han analitzat els orígens, entre 1835 i 1881, amb la desamortització de les biblioteques conventuals, o la de Daniel Gil, Imma Guzmán i Helena Fàbregas sobre la Biblioteca Pública Episcopal del Seminari a principis del segle $X X$.

\section{BIBLIOGRAFIA}

75 anys de l'Arxiu Històric de Tarragona (2019). Tarragona: Generalitat de Catalunya. Departament de Cultura, Arxiu Històric de Catalunya. <http://xac.gencat.cat/web/.content/xac/01 continguts arxius comarcals/ ah tarragona/11 75 anys/programa-75e-Aniversari-AHT.pdf>.

Algué Sala, Jordi. (2017) Rostres de Guerra. Cardona 1936-1938. Anàlisis, treball arxivístic, difusió I conservació del Fons de Retrats de la Guerra Civil. Treball final de màster dirigit per Maria Àngels Suquet Fontana. Escola Superior d'Arxivística i Gestió de Documents. Universitat Autònoma de Barcelona. <http://hdl.handle.net/2072/346694>.

Alturo Perucho; Alaix, Tània (2019). «El manuscrit més antic de la Vita et passio sancti desiderii de Sisebut copiat pel sacerdot Isarn de Vic i altres còdexs realitzats pel mateix amanuense». Miscel/lània litúrgica catalana. p. 193-210.

<https://www.raco.cat/index.php/Miscellania/article/view/369094>.
Els congressos que tenen Iloc

periòdicament a

Espanya sobre

biblioteques i arxius

no han tractat la

història de les

biblioteques o arxius

ni dels seus fons 
Alturo, Jesús; Alaix, Tània (2018). «El Virgili de Vic: breu avanç sobre la data, l'origen i l'autor de la còpia del còdex». Ausa, vol. 28, núm. 181-2, p. 851-7. <https://www.raco.cat/index.php/Ausa/article/view/352732>.

ANC : butlletí de l'Arxiu Nacional de Catalunya. Barcelona : Generalitat de Catalunya, Departament de Cultura.

$<$ http://anc.gencat.cat/web/.content/anc/Butlleti ANC/Butlletins/ANC54.p $\underline{\mathrm{df}>}$.

Anglada i Mas, Anna Maria (2019). «El Fons Miguel Casals Aragonés de la Biblioteca de Catalunya: el fil de vida d'un compositor desconegut». Revista Catalana de Musicologia, núm. 12, p. 331-345.

<http://revistes.iec.cat/index.php/RCMus/article/viewFile/146222/144745>.

Antón Pelayo, Javier (2018). «La desamortización de las bibliotecas conventuales en Cataluña durante la crisis del Antiguo Régimen» . Memoria y Civilización, núm. 21, p. 611-651.

<https://revistas.unav.edu/index.php/myc/article/view/34412>.

Arxivae: arxius de l'Alt Empordà. <http://arxivae.blogspot.com/>.

Biblioteca (2018). [Sallent: Ajuntament]. (Patrimoni Sallentí ; 2)

$<$ https://bibliotecasallent.files.wordpress.com/2018/03/fullet biblioteca $v$

3.pdf>.

La Biblioteca Popular de Valls (2018), per Laura Canalias, Lluís Cuspinera, Jep Martí, Jordi París, Núria Ventura. Valls: Institut d'Estudis Vallencs. (Per conèixer Valls; 12).

Cañizares Ferriz, Patricia (2018). «Aliqua exempla et miracula: una pequeña colección de relatos en el ms. 3171 de la Biblioteca de Catalunya». Revista de estudios latinos: RELat, núm. 18, p. 89-115.

$<$ https://www.relat.org/relat/index.php/relat/article/view/260>.

Capdevila Arrizabalaga, Irene (2018). "Un Manuscrit Perdut: El "Breviari " català de la Biblioteca del Palau». Mot so Razo, v. 17, p. 38-51. <https://www.raco.cat/index.php/Msr/article/view/362278>.

Capellades i Riera, Alan (2018). «Navegant pel fons documental de I'Institut Industrial». Terme, núm. 33, p. 109-24.

<https://www.raco.cat/index.php/Terme/article/view/360294>.

Castejón Domènech, Nativitat (2019). Benvingut Socias Mercadé (1877 1952), un músic vendrellenc per descobrir. Estudi del seu llegat a I'Arxiu Comarcal del Baix Penedès. [Barcelona]: Generalitat de Catalunya. Departament de Cultura; [El Vendrell]: Consell Comarcal del Baix Penedès.

Castellano Tudela, Neus (2018). El servei de documentació de literatura infantil i juvenil (SDLIJ) de la Biblioteca Xavier Benguerel de Barcelona. Història, situació actual i propostes de futur.

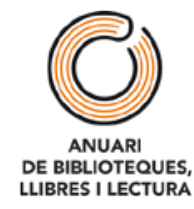


Treball final de grau dirigit per Teresa Mañà. Facultat de Biblioteconomia i Documentació, Universitat de Barcelona.

<http://hdl.handle.net/2445/125419>.

Comalat Navarra, Maite (2018). El bibliobús, una oportunitat per a una societat xarxa. Anàlisi del servei a Espanya i recomanacions. Tesi doctoral dirigida per Teresa Mañà. Facultat de Biblioteconomia i Documentació, Universitat de Barcelona. <http://hdl.handle.net/2445/126623>.

Corbella i Corbella, Jacint; Cama i Socías, Daniel; Jaular i Aulet, Irene; Alpáñez López, Carme (2019). "El fil per cosir la història... de la medicina". Gimbernat: Revista d'Història de la Medicina i de les Ciències de la Salut, vol. 71, p. 83-186.

<https://www.raco.cat/index.php/Gimbernat/article/view/360985>.

Cuadrada, Coral (2018). "L'Arxiu dels Marquesos de Santa Maria de Barberà», a Cuadrada, Coral, Garriga, Montserrat (coords.). El rescat de les cent donzelles o de sant Esteve. Manuscrit de la Genealogia del llinatge Pinós, 1620. Arxiu dels Marquesos de Santa Maria de Barberà. Tarragona: Publicacions Universitat Rovira i Virgili, p. 23-56.

Cuadrada, Coral; Duran Duelt, Daniel; Martínez-Giralt, Alejandro (2018). El fons Llull de l'Arxiu dels Marquesos de Santa Maria de Barberà. [Tarragona]: Publicacions URV; [Barcelona]: IEMED Institut Europeu de la Mediterrània. <http://llibres.urv.cat/index.php/purv/catalog/view/332/345/788-1>.

De Puig Oliver, Jaume (2018). "Els cinc documents ripollesos del segle $X$ conservats a I'Arxiu Capitular de Girona». Annals de I'Institut d'Estudis Gironins, vol. 59, p. 131-156.

<https://www.raco.cat/index.php/AnnalsGironins/article/view/356234>.

De Puig Oliver, Jaume (2019). «Vint Documents Gironins De l'Arxiu Històric Nacional De Madrid». Annals De l'Institut d'Estudis Gironins, vol. 60, p. 139. <https://www.raco.cat/index.php/AnnalsGironins/article/view/362361>.

Diplomatari de la catedral de Tortosa: episcopats de Ponç de Torrella (12121254) i Bernat d'Olivella (1254-1272) (2018). Edició a cura de: Antoni Virgili, Josep Maria Escolà, Manel Pica, Montserrat Rovira. Barcelona: Fundació Noguera.

Dolcet, Josep (2019). «Josep Maria Llorens i Cisteró». Revista Catalana de Musicologia, núm. 12, p. 7-9.

<https://publicacions.iec.cat/repository/pdf/00000281/00000080.pdf>.

Enfedaque Novell, Jordi (2018). «El Fons documental Sebastià Juan Arbó al Servei d'Arxiu Municipal de Sant Carles de la Ràpita». Beceroles: Lletres de llengua i literatura, núm. 7, p. 13-22.

<https://www.raco.cat/index.php/Beceroles/article/view/336940/427751>. 
Erra, Ramon; il.lustració: Pilarín Bayés (2018). Petita història del la Biblioteca de Canet de Mar. Barcelona: Editorial Mediterrània.

Dolcet, Josep (2019). «Josep Maria Llorens i Cisteró». Revista Catalana de Musicologia, núm. 12, p. 7-9.

<https://publicacions.iec.cat/repository/pdf/00000281/00000080.pdf>.

Esteller Mas, Montse; Macià Farré, Marc; Varela Serra, Josep (2018). Centenari Biblioteca Popular les Borges Blanques : 1918-2018. Les Borges Blanques: Ajuntament de Les Borges Blanques.

Fernández Dobón, Sònia (2019). «Biblioteca Infantil i Juvenil Can Butjosa: 25 anys portant bons llibres a les escoles». Guix: Elements d'acció educativa, núm. 454, p. 43-47.

El Fons del "Archivo Fotográfico de Villanueva y Geltrú": la Secció fotogràfica del Centre d'Estudis de la BMB (2018). Selecció i tractament fotogràfic: Rafel Mestres Boquera i Sílvia Manuel Lafuente. Vilanova i la Geltrú: El Cep i la Nansa Edicions: Arxiu Comarcal del Garraf, desembre (Els Nostres fotògrafs; 6 ).

Gil Solés, Daniel; Guzmán Fernández, Imma; Fàbregas Rebato, Helena (2019). "La Biblioteca Pública Episcopal del Seminari a principis del segle XX». A: Elias Rogent i Barcelona. Arquitectura, patrimoni i restauració. [Barcelona]: Universitat de Barcelona; Diputació Barcelona; Seminari Conciliar de Barcelona.

González Ruiz, David; Marcos Bayona, David (2018). "L'enigma del Niu Trobat». Arraona: revista d'història, núm. 37, p. 202-9.

<https://www.raco.cat/index.php/Arraona/article/view/343267>.

González Pérez, Anna (2019). El paper dels arxius en la construcció dels Estats-Nació: França i Espanya. Treball final de màster. Escola Superior d'Arxivística i Gestió de Documents.

$<$ http://hdl.handle.net/2072/366958>.

Gregori i Cifré, Josep Maria (2019). Fons de la Catedral de Girona. Bellaterra: Universitat Autònoma de Barcelona; Barcelona: Institut d'Estudis Catalans. (Inventaris dels fons musicals de Catalunya; 10)

Gros i Pujol, Miquel dels Sants (2018). «Fragments de passioner i de leccionari del santoral de la Biblioteca Episcopal de Vic dels segles IX-XIII». Miscel·lània litúrgica catalana, núm. 11, p. 97-145.

<https://www.raco.cat/index.php/Miscellania/article/view/347912>.

Gudayol, Anna (2019). "L'arribada dels cançoners Vega a la Biblioteca de Catalunya». Plecs d'història local, núm. 174, p. 8-10.

<https://www.raco.cat/index.php/Plecs/article/view/360608>.

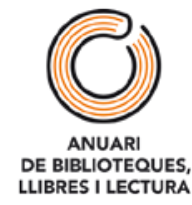


Gudayol Torelló, Anna (2019). «Jaume Riera i Sans (Sant Feliu de Llobregat, 1941-Tarragona, 2018)». Estudis Romànics, any 2019, p. 718-723. <https://www.raco.cat/index.php/Estudis/article/view/353864>.

Janeras, Sebastià (2019). "Nota sobre l'anamnesi de I'"Anàfora de Barcelona ": (P. Monts. Roca Inv. 128-178) : recordant el pare Alexandre Olivar, mestre i amic admirat». Miscel.lània litúrgica catalana, vol. 27, p. 1724. <https://publicacions.iec.cat/repository/pdf/00000281/00000038.pdf>.

Jansà i Cuatrecasas, M. Enriqueta (2019). Petita història de Procés Tècnic: una visió de la informatització del fons documental a la Universitat de Barcelona. Barcelona: Edicions de la Universitat de Barcelona. (Biblioteca Universitària. Universitat de Barcelona)

López Rodríguez, J. A. (2019). «Recuperació de l'Arxiu de l'Escola de Treball Social de la Universitat de Barcelona». Revista de Treball Social, núm. 215, p. 93-105. <doi:10.32061/RTS2019.215.06>.

Maimir, Anna (2018). "Can Comas i el fons documental de l'empresa Unitesa a l'Arxiu Municipal de Granollers». Ponències: Revista del Centre d'Estudis de Granollers, núm. 22, p. 163-178.

<https://www.raco.cat/index.php/Ponencies/article/view/349227/440389>

Mañà, Teresa (2018). «Biblioteques a l'aire lliure. Els bancs biblioteca del passeig de Sant Joan de Barcelona (1930)». BiD: textos universitaris de biblioteconomia i documentació, núm. 41 (desembre).

<http://bid.ub.edu/41/mana.htm>.

Martí Baiget, Pep (2018). "La Biblioteca Popular de Valls : cent anys de la xarxa de biblioteques de Catalunya». Cultura i paisatge a la ruta del Císter, núm. 11, p. 6-8

Martí Pou, Sara (2019). L'adquisició de béns del patrimoni documental de Catalunya. Treball final de màster dirigit per Remei Perpinyà. Escola Superior d'Arxivística i Gestió de Documents.

<https://recercat.cat//handle/2072/364537>.

Nadal i Farreras, Joaquim (2019). "'Un gris verdós, clar, si l'ensopeguen, pot fer bonic". Biblioteques i guerra: una correspondència de Jordi Rubió $\mathrm{i}$ Balaguer amb Joan Subias i Galter (1927-1938)». A: República i guerra civil a Girona: estudis i documents. Girona: Documenta Universitària. (Institut Català de Recerca en Patrimoni Cultural; 17).

Ortiz Ezquerra, J. (2019). Records individuals, memòries col-lectives: donació i tractament arxivistic de la col-lecció Jubilats de MACOSA-Alstom a l'Arxiu Municipal del Districte de Sant Martí. Treball final de màster dirigit per Miquel Pérez Latre. Escola Superior d'Arxivística i Gestió de Documents. <http://hdl.handle.net/2072/364039>.

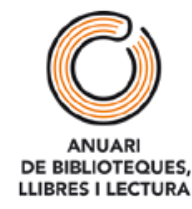


Pérez López, Gal·la (2019). La correspondència comercial del llibreter Josep Porter i Rovira a la Biblioteca de Catalunya: una primera aproximació a l'estudi del circuit de compra-venda del llibre d'antiquària a Barcelona. Memòria del màster en Biblioteques i Col-leccions Patrimonials.

Facultat de Biblioteconomia i Documentació, Universitat de Barcelona.

Perrotta, Carmen (2018). De la toga a la cámara fotográfica: Adolf Mas Ginestà (1860-1936). Innovación archivística al servicio del arte románico. Tesi doctoral dirigida per Carles Mancho i María de los Santos García Felguera. Facultat de Geografia i Història, Universitat de Barcelona. <http://hdl.handle.net/10803/565538>.

Perrotta, Carmen (2018). "L'Arxiu Mas de Barcelona. L'ull, la càmera i l'art espanyol». Locus Amoenus, vol. 16, núm. 1, p. 251-272. $<$ https://www.raco.cat/index.php/Locus/article/view/v16-perrotta>.

Pessarrodona i Pérez, Aurèlia (2019). "Cimarosa a la Garrotxa:: recepció i pràctica domèstica de l'òpera italiana del segle XVIII $\mathrm{i}$ inicis del segle XIX a Olot». Revista catalana de musicologia, núm. 12, p. 223-258. $<$ http://revistes.iec.cat/index.php/RCMus/article/viewFile/146218/144741

$>$.

Pinyol Balasch, Jaume (2019). «Músics empordanesos a la catedral de Girona durant el segle XVIII. Una aproximació». Annals de I'Institut d'Estudis Empordanesos, núm. 50, p. 175-189.

$<$ https://www.raco.cat/index.php/AnnalsEmpordanesos/article/view/3631 $\underline{47 / 457556>}$.

Planagumà Clarà, Laura (2019). Amors, peregrines i ronya : estudi d'un cançoner d'Olesa de Montserrat. Treball final de Grau. Escola Superior de Música de Catalunya. <http://hdl.handle.net/2072/368021>.

Planes Albets, Ramon (2018). L'Arxiu de Josep Puig i Cadafalch. Solsona: Arxiu Comarcal del Solsonès.

Puentes-Blanco, Andrea (2019). Música y devoción en Barcelona (ca. 15501626): estudio de libros de polifonía, contextos y prácticas musicales. Tesi doctoral dirigida per Emilio Ros-Fábregas. Facultat de Geografia i Història, Universitat de Barcelona. <http://hdl.handle.net/10803/666286>.

Puig, Evarist (2018). «Vuitanta anys de biblioteca». Revista de Palafrugell, núm. 297, juliol, p. 34-35.

Riera, Sebastià (2018). "L'Arxiu Històric de la Ciutat de Barcelona: una institució al servei del patrimoni, la informació, la recerca i la cultura». A: Caballé, Francesc; González, Reinald. La Casa de l'Ardiaca de Barcelona : dos mil anys d'història. Barcelona: Ajuntament de Barcelona; Arxiu Històric de la Ciutat.

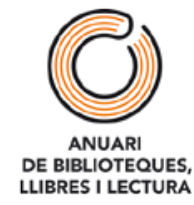


Rius i Bou, Àngels (2019). Relació dels llibres procedents de l'antic hospital militar de Montserrat durant la Guerra Civil existents a la Biblioteca de Montserrat : 1938-1939. Montserrat: Biblioteca de Montserrat.

Ruiz, Marina; Verger, Neus (2019). "Dels convents a l'acadèmia: els orígens de la biblioteca de la Universitat de Barcelona (1835-1881)». A: Elias Rogent i Barcelona: arquitectura, patrimoni i restauració. Edicions de la Universitat de Barcelona. <http://diposit.ub.edu/dspace/handle/2445/121374>.

Ruiz Ruiz, Yolanda (2018). «L'adquisició de llibres feta per Salvador Sanpere i Miquel l'any 1890, origen de la Biblioteca Joaquim Folch i Torres del Museu Nacional d'Art de Catalunya». Matèria: revista d'art, núm. 13, p. 3550. <https://www.raco.cat/index.php/Materia/article/view/347862>.

Salisi i Clos, Josep M (2019). «Destacat corpus musical d'autors de la catedral de Lleida a l'arxiu capitular d'Albarrasí: cent anys de documentació musical conservada». Shikar, núm. 6, p. 66-72.

<https://www.raco.cat/index.php/Shikar/article/view/366549>.

Salisi i Clos, Josep Maria (2019). "L'obra de Joan Cererols al Fons Verdú de la Biblioteca de Catalunya. El pare David Pujol i la publicació a Mestres de I'escolania de Montserrat». Revista catalana de musicologia, vol. 12, p. 115134.

<http://revistes.iec.cat/index.php/RCMus/article/viewFile/146213/144736 $>$.

Sarrà, Esther; Sánchez, Paloma (2018). Catàleg de la col/lecció de naips de I'Arxiu Històric de la Ciutat de Barcelona (1529-1988). Barcelona: Arxiu Històric de la Ciutat de Barcelona.

$<$ https://ajuntament.barcelona.cat/arxiumunicipal/arxiuhistoric/sites/defau It/files/cataleg colleccio naips ahcb 0.pdf $>$.

Sesma Siuraneta, Mònica (2018). "Els fons de Particulars de l'Arxiu Municipal de Lleida: l'arxiu de la ciutat». Shikar, núm. 5, p. 165-170. <https://www.raco.cat/index.php/Shikar/article/view/350584>.

Simon, Carmen; Mayans, Antoni (2018). Centenari Biblioteca Popular d'Olot: 1918-2018. Olot: Institut Municipal de Cultura d'Olot.

Torras Cortina, Miquel (2018). "Un catàleg de manuscrits del segle XVIII de la biblioteca de la catedral de Vic redactat pel P. Jaume Pasqual per als Sacrae antiquitatis cataloniae monumenta». Miscel/lània litúrgica catalana, núm. 26, p. 343-359.

<https://www.raco.cat/index.php/Miscellania/article/view/347918>.

Vas Rafael, Juanjo (coordinador). El Pergamí de 1588, el capbreu de Pere Térmens : Fons Salvador Savall de l'Arxiu Municipal de Castelldefels (2018). Autors: Juanjo Cas Rafael, Josep Campmany Guillo, Alba Gómez i Clavell, Carme Muntaner i Alsina. Castelldefels: Ajuntament de Castelldefels. 
Ventosa Molner, Francesc Xavier (2018). Els usos musicals a la Cardona del 1700 : una aproximació a partir dels registres de comptabilitat en el període 1686-1737. Treball final de grau. Escola Superior de Música de Catalunya. <http://hdl.handle.net/2072/355739>. 
https://revistes.ub.edu/index.php/Anuari-BLL/article/view/32941

Losantos, Marga. "Història de les biblioteques i els arxius a Catalunya (2018-2019)». Anuari de Biblioteques, Llibres i Lectura, vol. 6 (2020), p. 182-201.

DOI 10.1344/ABLL.2020.6.010

Llicència Creative Commons

Reconeixement - NoComercial - SenseObraDerivada

(by-nc-nd): No es permet un ús comercial de l'obra

original ni la generació d'obres derivades.

(c) (1) ()요 


\title{
ANUARI
}

\section{DE BIBLIOTEQUES, \\ LLIBRES I LECTURA}

2020

\section{Editors}

\author{
Lluís Agustí \\ Maite Comalat
}

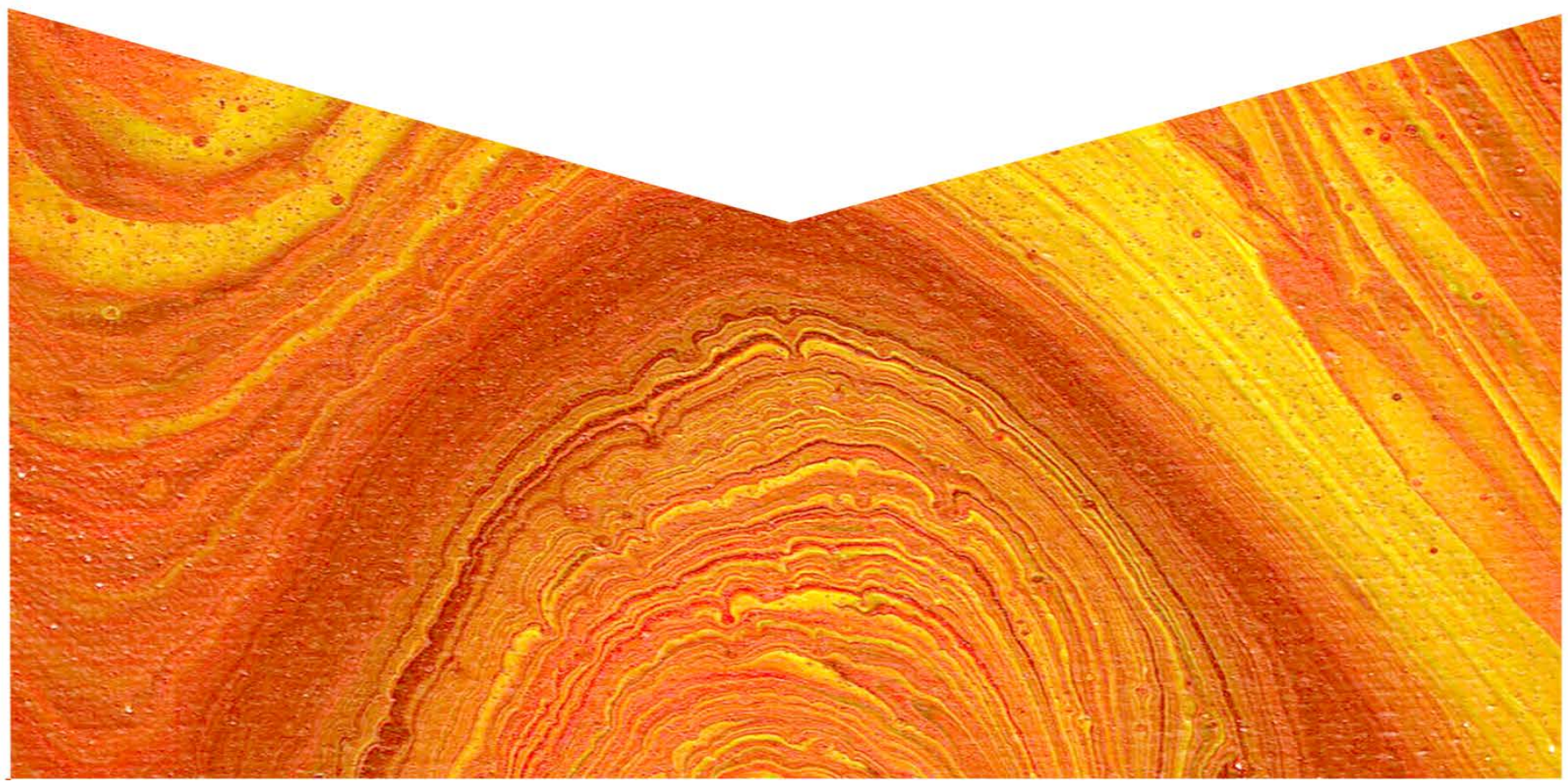

